\title{
Finite Element Study of The Buckling of Cracked Thin Plates Repaired by Composite Laminate Under Compression
}

\author{
Qiang Liu ${ }^{1}$, Liankun Wang1*, Jiong Zhang ${ }^{1}$, Qiang Tang ${ }^{1}$ and Weidong Liu ${ }^{2}$ \\ ${ }^{1}$ School of Civil Engineering and Architecture, Wuyi University, China \\ ${ }^{2}$ College of Energy and Electrical Engineering, Hohai University, China
}

*Corresponding author: Liankun Wang, School of Civil Engineering and Architecture,

Received Date: August 14, 2019

Wuyi University, Dongcheng Village, China.

\section{Abstract}

In this paper, the elastic buckling of cracked thin plates repaired by composite laminate patch under compression was studied by the finite element method. The effects of the shape of the repairing patch, size of the repairing patch, and the thickness of the patch on the elastic buckling load were evaluated. The results show that the size and thickness of the repairing patch must be optimized to increase the performance of the repairing.

Keywords: Thin plate; Finite element; Buckling analysis; Composite material

\section{Introduction}

Thin plates are one of the main structural forms in engineering. The buckling of the thin plate has attracted much attention in the past few decades. However, the crack problems usually arise when the thin plate is subjected to cyclic loadings, which will decrease the buckling load of the thin plate. Therefore, strengthening the cracked plate by a composite patch is an effective way to increase the buckling load.

Most of the previous studies have focused on the buckling analysis of the damaged plates or cracked plates. Lin Dongliang [1] studied the buckling performance of thin plates containing singlerow circular holes under unidirectional non-uniform compression. Several parameters on the buckling capacity of the perforated plates were studied. Hou Xianglin [2] employed the finite element method to analyze the buckling behaviors of the simply supported open-walled plates under axial compression. Brighenti [3-5] analyzed the buckling problem of cracked rectangular elastic sheets with different geometrical dimensions, boundary conditions, and bearing modes. Seifi and Khoda-yari [6] conducted experimental and numerical studies on the buckling of cracked plates under full compression and partial edge compression. The effects of crack location, plate thickness, and boundary conditions on the buckling load were studied. Miao Xuezhou [7] studied the repairing effects by the finite element method. Their results show that important design parameters that have a significant impact on the final failure load of the motherboard.

As a new structural repairing technique, composite patch bonding repair technology has its own advantages compared with traditional mechanical repairing technology and can improve the strength of the damaged plate. Therefore, predicting the buckling behavior of the repaired structures can improve the repair design of damaged structures. So, in this paper, the finite element method was used to analyze the buckling of the cracked thin plates. The parameters of the cracked plates such as the shape and size of the patch and the thickness of the rubber layer on the repairing effects were considered.

\section{Geometric Model}

The geometric dimensions and material parameters of the model in this study are the same as those in the study by Zhang [8] as shown in Figure 1. A steel plate contains a circular hole in the middle and two cracks on both sides of the circular hole. The detailed dimensions are included as follows: height $\mathrm{H}=120 \mathrm{~mm}$, 
width $\mathrm{W}=80 \mathrm{~mm}$, thickness $\mathrm{t}=3 \mathrm{~mm}$, hole radius $\mathrm{R}=5 \mathrm{~mm}$, elastic modulus E=200000Mpa, Poisson's ratio $r=0.3$.

The material properties of the patch are as follows:

$$
E_{1}=138000 \mathrm{Mpa}, \quad E_{2}=9700 \mathrm{Mpa}, \quad E_{3}=9700 \mathrm{Mpa} \text {, }
$$

$$
\begin{aligned}
& G_{12}=9700 \mathrm{Mpa}, G_{13}=6900 \mathrm{Mpa}, G_{23}=3200 \mathrm{Mpa}, v_{12}=0.28, \\
& v_{13}=0.28, v_{23}=0.02 .
\end{aligned}
$$

The binder is made of FM73 rubber, and its material properties are as follows : $E=2200 \mathrm{Mpa}, P_{s}=37 \mathrm{Mpa}$.
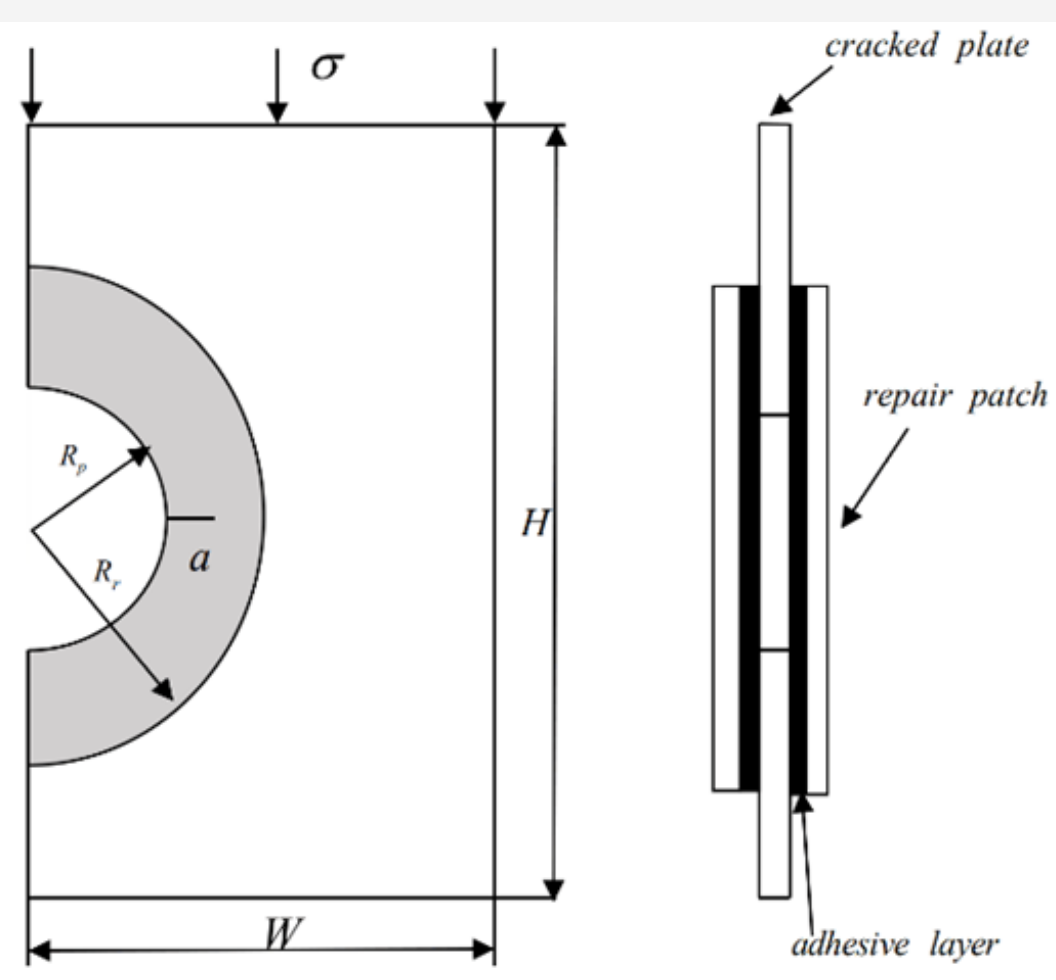

Figure 1: Geometrical model of the patched structure.

\section{Finite Element Model}

In this paper, ABAQUS was used to perform the eigenvalue buckling analysis of this structure. The finite element model consisted of three parts: the cracked plate, the glue layer, and the repairing patch. Due to symmetry, only half of the structure was created in the finite element study. The tie layer was used between the repairing patch and cracked plate. Figure 2 shows a typical mesh mode and boundary conditions for the entire structure.

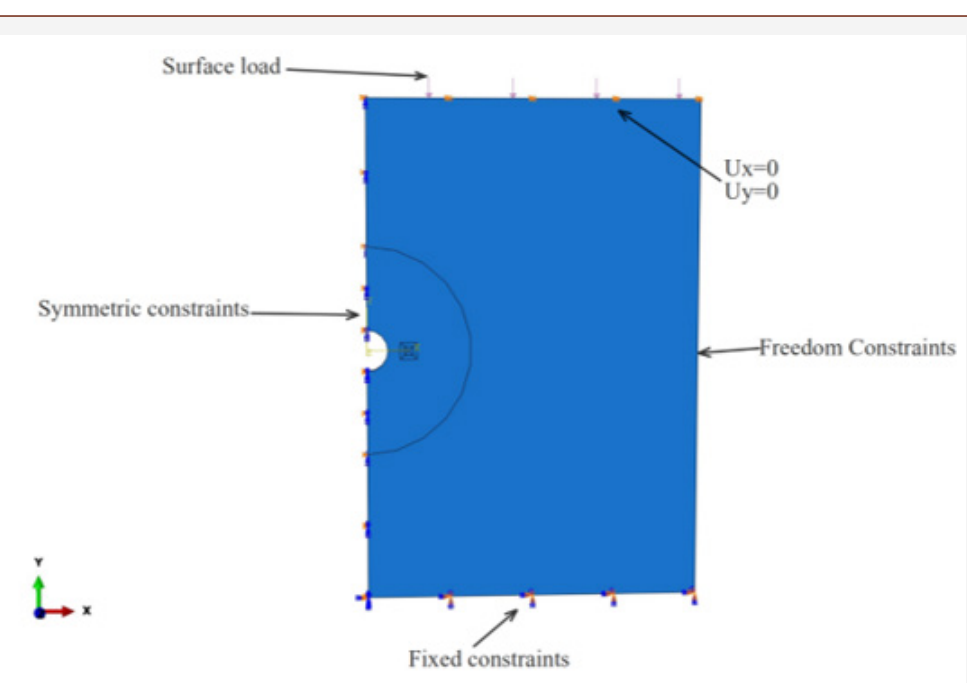

(a)

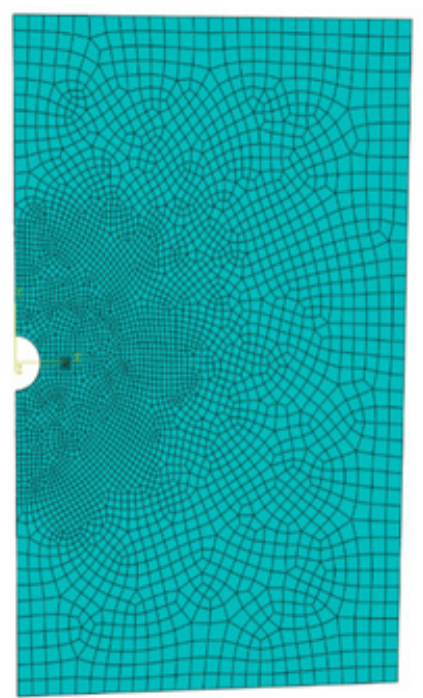

Figure 2: Model of the structure: (a) finite element model and boundary conditions (b) mesh of the model. 


\section{Results}

\section{Effect of the patch shape on the buckling load}

Four kinds of repairing patch, including the circular patch, quadrilateral patch, and regular hexagon patch were selected in this paper to analyze and compare the repairing effects of different patches. Detailed descriptions of the patches are shown in Figure 3.

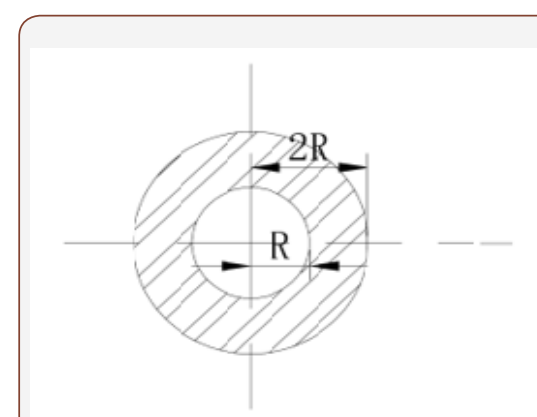

(a) shape 1

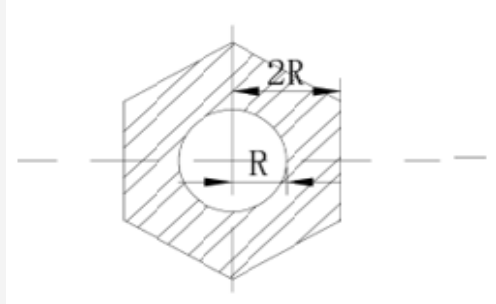

(C) shape 3

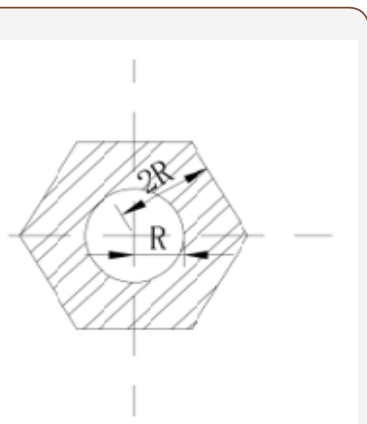

(b) Shape 2

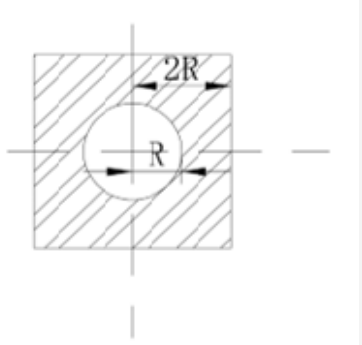

(d) shape 2

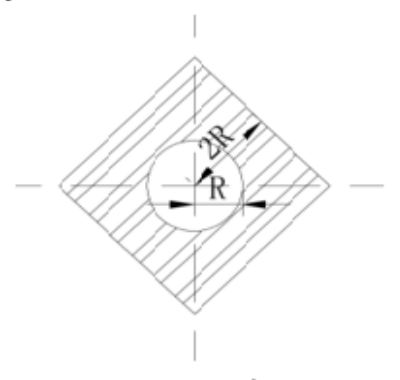

(e) shape 5

Figure 3: Five different shapes of patches.

The thickness of the patch was fixed at $1 \mathrm{~mm}$, and the thickness of the adhesive layer was $0.2 \mathrm{~mm}$. In this paper, the buckling loads of the cracked plate with repairing and without repairing were both calculated. The results are shown in Figure 4. As we can see in Figure 4, the repairing patch can obviously improve the stability of the cracked plate. However, the shape of the patch has little effects on the improvement of the buckling loads. Comparing the first order buckling mode of the cracked plate without patch and with No. 4 patch, it is found that the first order buckling mode of the cracked plate is the same. However, compared with the unrepaired structure, the stiffness of the plate is improved, which can be seen from the first order buckling mode diagram (Figure 5). The lateral displacement of the motherboard is significantly suppressed. The first order buckling mode here consistent with the structural buckling deformation observed in the compression experiments in the literature [9].

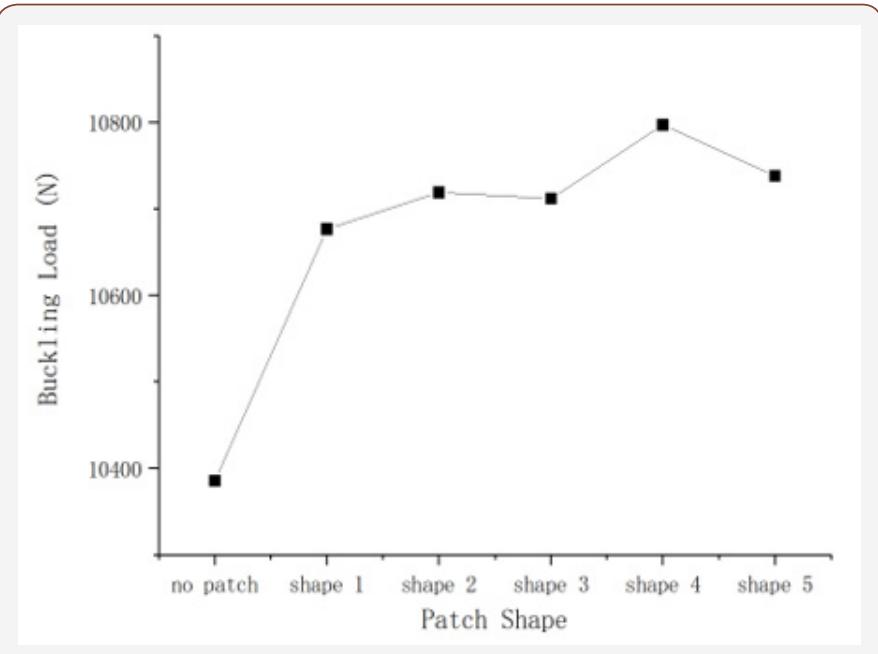

Figure 4: Buckling load for five different types of patches.

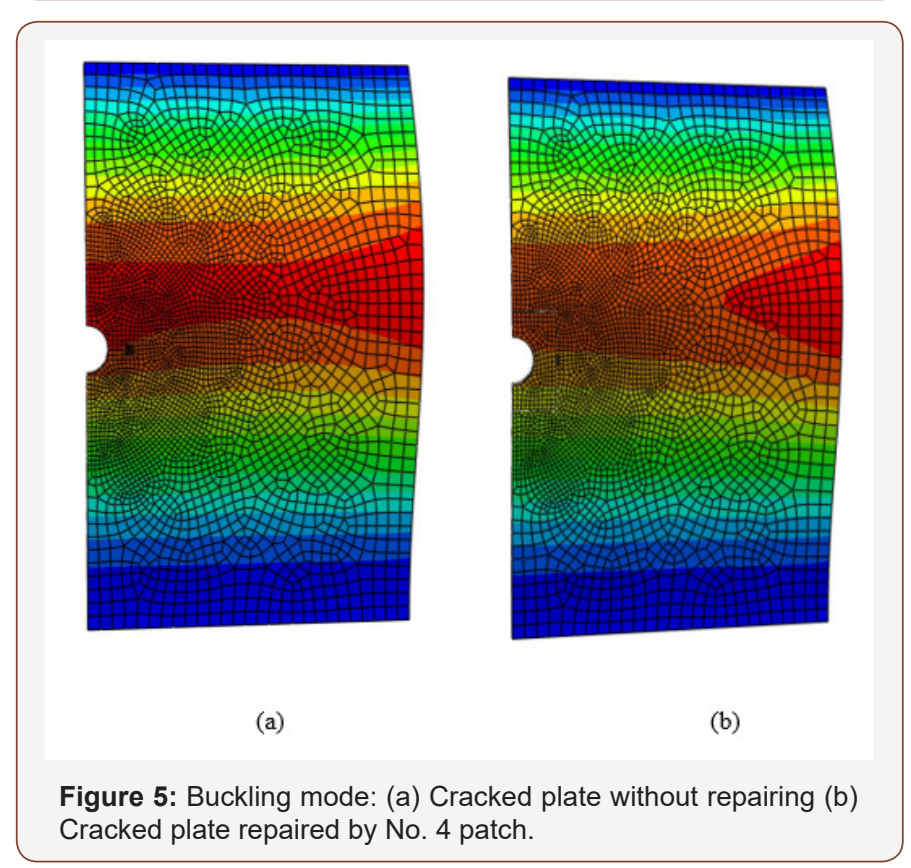

\section{Effect of the patch radius on the buckling load}

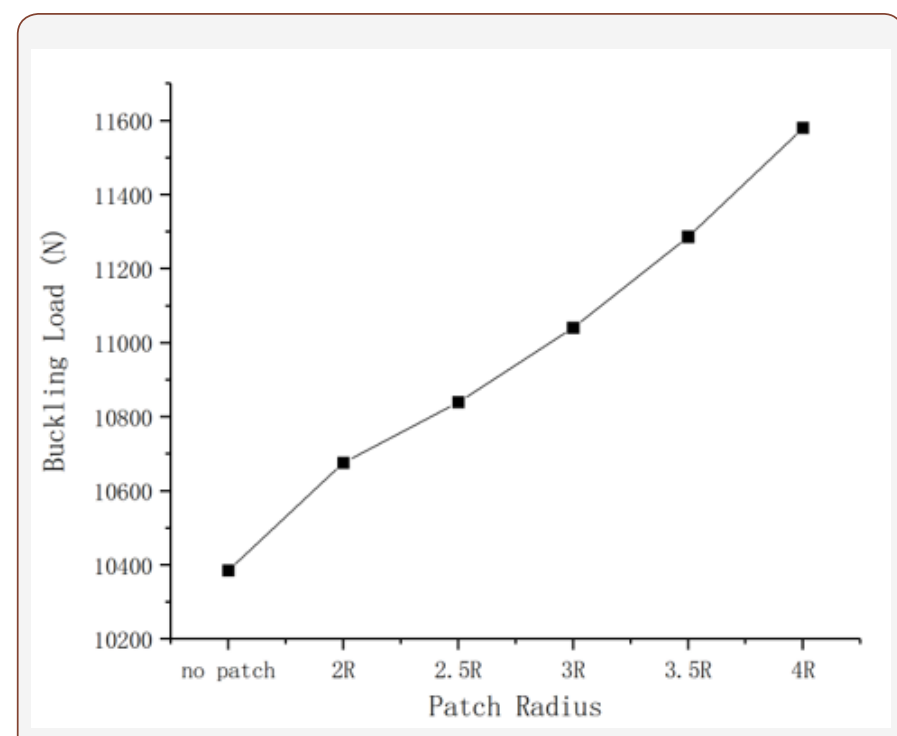

Figure 6: Buckling loads for different patch radius. 
In order to study the size of the repairing patch on the buckling load, five radiuses ( $R, 2 R, 2.5 R, 3 R, 3.5 R$, and $4 R$ ) of the circular patch are selected in this paper. Here, the buckling loads of the patched composite laminates of radius were calculated by keeping the thickness of the patch at $1 \mathrm{~mm}$ and the thickness of the glue layer at $0.2 \mathrm{~mm}$. The results are shown in Figure 6.

The results show that the buckling loads increase with the increase of the patch radius. We can also see that when the patch radius increases from $2 \mathrm{R}$ to $5 \mathrm{R}$, the buckling load increases by $8 \%$ which indicates that the repairing effects can be improved by increasing the patch radius in the actual repair work.

\section{Effect of the patch thickness on the buckling load}

The circular patch was selected to study the effect of the patch thickness on the buckling load. In this study, the diameter of the patch was fixed at $3 \mathrm{R}$, and the patch thickness varied from $0.6 \mathrm{~mm}$ to 2.2 mother results are shown in Figure 7.

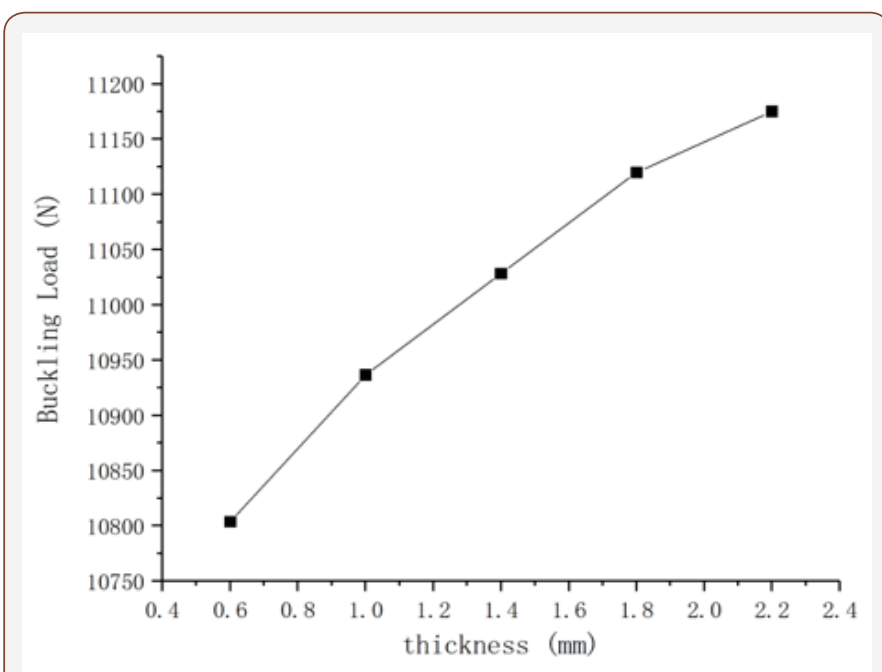

Figure 7: Buckling load for different patch thicknesses.

As can be seen from Figure 7, the buckling load of the plate increases with the increase of the patch thickness. When the patch thickness increased from $0.6 \mathrm{~mm}$ to $2.2 \mathrm{~mm}$, the buckling load of the repaired structure increased by $3 \%$.

\section{Conclusion}

- The finite element method was used to study the buckling behavior of the cracked plate repaired by composite patch under compression.
- $\quad$ Compared with other shapes of the repairing patch, the square patch has the most improvement in buckling load.

- The radius and the thickness of the repairing patch are the most important factors to improve the repairing effect and increase the buckling load of the cracked plate.

\section{Acknowledgement}

None.

\section{Conflict of Interest}

No conflict of interest.

\section{References}

1. Dongliang Lin, Shaofeng Yu (2012) Analysis of Buckling Bearing Capacity of Unidirectional Non-uniformly Compressed Opened Plates [J]. Low Temperature Architecture Technology 12(12): 51-53.

2. Xianglin HOU, Xiaocheng SUN, Lianguang JIA, Chungang WANG, Jing Feng DU (2012) Finite Element Analysis of Local Stability of Simply Supported Plates with Hexagon Holes under Axial Compression [J]. Journal of Shenyang Jianzhu University (Natural Science) 28(2): 234240.

3. Brighenti R (2005) Numerical buckling analysis of compressed or tensioned cracked thin plates. Eng Struct 27: 265-276.

4. Brighenti R (2005) Buckling of cracked thin plates under tension or compression. Thin Walled Struct 43: 209-24.

5. Brighenti R (2010) Influence of a central straight crack on the buckling behavior of thin plates under tension, compression or shear loading. Int J Mech Mater Des 6: 73-87.

6. Seifi R, Khoda yari N (2011) Experimental and numerical studies on buckling of cracked thin plates under full and partial compression edge loading. Thin Walled Struct 49: 1504-1516.

7. Xuezhou MIAO, Cheng LI, Ying TIE, Wenhui GUO (2014) Influence of Patch Shape and Size on Adhesively Bonded Composite Repair. Journal of Mechanical Engineering 50(20): 63-69.

8. Jiong Zhang, Zhan Qu, Qiqing Huang (2014) The debonding failure analysis of cracked metallic plate with bonded composite semicircular patch at notch.Archive of Applied Mechanics 84(5) : 731-742.

9. RDSG Campilho, MFSF, De Moura, DA Ramantani, et.al. (2010) Buckling strength of adhesively bonded single and double-strap repairs on carbon-epoxy structures. Composites science and technology 70(2): 371-379. 